\title{
DESENVOLVIMENTO E CARACTERIZAÇÃO DE DIFERENTES FORMULAÇÕES DE SORVETES ENRIQUECIDOS COM FARINHA DA CASCA DA JABUTICABA (Myrciaria cauliflora)
}

\author{
Development and characterization of ice cream enriched with \\ different formulations flour jabuticaba bark (Myrciaria cauliflora)
}

\author{
Marina Leopoldina Lamounier ${ }^{*}$, Fabricia das Chagas Andrade ${ }^{l}$, \\ Cristina Dias de Mendonçal, Maísa Lamounier Magalhães ${ }^{l}$
}

\section{RESUMO}

O objetivo foi realizar a caracterização físico-química da farinha da casca de jabuticaba, bem como desenvolver três formulações de sorvetes (enriquecidos com 0,5 e $10 \%$ desta farinha) e avaliar as características físico-químicas e sensoriais dos mesmos. Os frutos foram despolpados, as cascas desidratadas, trituradas e peneiradas para obtenção da farinha que foi analisada quanto aos teores físico-químicos. Em seguida, foram desenvolvidas três formulações de sorvetes (com $0 \%$, $5 \%$ e $10 \%$ de FCJ) e, verificadas as características físico-químicas e sensoriais. Os resultados mostraram que a FCJ apresentou alto teor de cinzas e fibras. Já os sorvetes, apresentaram diferença $(\mathrm{p}<0,05)$ para $\mathrm{pH}$, acidez titulável, umidade e cinzas devido a incorporação da FCJ. O único atributo que não se diferenciou $(\mathrm{p}>0,05)$ foi o sólido solúvel. O overrun foi diminuindo conforme o aumento da adição da farinha. Já na análise sensorial, os únicos atributos que se diferenciaram $(\mathrm{p}<0,05)$ foram sabor, textura e aspecto global da formulação com 10\% de FCJ, o que representa que a incorporação de 5\% de FCJ não interferiu na aceitabilidade dos sorvetes. Pode-se concluir que o enriquecimento da farinha da casca de jabuticaba proporciona aos gelados comestíveis elevação no valor nutricional sem afetar as características sensoriais ao nível de 5\% de adição.

Palavras-chave: gelado comestível; alimento funcional; fruta tropical.

1 Instituto Federal de Educação Ciência e Tecnologia Minas Gerais (IFMG), Campus Bambuí, Fazenda Varginha, km 05, Caixa Postal 05, 38900-000, Estrada Bambuí/Medeiros, Bambuí, MG, Brasil.

E-mail: marina.lamounier@ifmg.edu.br

* Autor para correspondência.

Recebido / Received: 10/02/2015

Aprovado / Approved: 15/06/2015 


\begin{abstract}
The aim was to perform the physicochemical characterization of the flour from the bark of jabuticaba, as well as developing three ice cream formulations (enriched with 0,5 and $10 \%$ of this flour) and evaluate the physicochemical and sensory characteristics. Fruits were pulped, the peels were dehydrated, dried, crushed and sieved to obtain the flour that was analyzed for physicochemical levels. Then, three ice cream formulations were developed (with $0 \%, 5 \%$ and $10 \%$ flour from the bark of jabuticaba), considering the physicochemical and sensorial characteristics. The results showed that the flour from the bark of jabuticaba showed high ash and fiber. The ice creams showed differences $(\mathrm{p}<0.05)$ for $\mathrm{pH}$, titratable acidity, moisture and ash due to the incorporation of flour from the bark of jabuticaba. The only attribute that did not differ $(\mathrm{p}>0.05)$ was soluble solid. The overrun was decreasing with increasing addition of flour. In the sensory evaluation, only attributes that differ $(\mathrm{p}<0.05)$ were flavor, texture and overall appearance of the formulation with $10 \%$ flour from the bark of jabuticaba, which represents that incorporation of $5 \%$ flour from the bark of jabuticaba did not affect the acceptability of ice creams. It can be concluded that the enrichment of blemish bark flour provides edible ice increase in nutritional value without affecting the sensory characteristics at the level of $5 \%$ added.
\end{abstract}

Keywords: ice cream; functional food; tropical fruit.

\section{INTRODUÇÃO}

O desenvolvimento de alimentos funcionais é um campo que está repleto de oportunidades, pois o consumidor busca produtos que supram suas necessidades nutricionais. Além disso, espera-se que esses alimentos possam contribuir para o fortalecimento da saúde e manutenção do bem-estar, retardando ao máximo o aparecimento de doenças (WORLD HEALTH ORGANIZATION, 2009; ALISSA; FERNS, 2012).

Por outro lado, segundo dados da Pesquisa de Orçamento Familiar (POF) realizada em 2008-2009, a desnutrição, nos primeiros anos de vida é um problema de grande relevância para a saúde pública no Brasil (IBGE, 2010) e esse fato pode ser justificado pela ausência do consumo de determinados nutrientes essenciais para o bom funcionamento do organismo. Dentre estes alimentos, encontram-se as fibras, vitaminas, sais minerais e pigmentos naturais como as antocianinas, as quais podem reduzir a incidência de doenças cardiovasculares, obesidade, entre outras enfermidades causadas pela má ingestão de alimentos.

A jabuticaba (Myrcia cauliflora Berg) é uma fruta nativa do Brasil e é conhecida desde o período do descobrimento. É uma fruta rica em vitaminas, antocianinas, fibras e sais minerais, entretanto, esses nutrientes estão em maior concentração na sua casca, parte que geralmente é descartada. Uma opção para o consumo desses nutrientes é a incorporação das cascas da jabuticaba em alimentos, principalmente por ser considerado um corante natural que apresenta elevados teores de antocianinas, proporcionando, desta forma, ação antioxidante (ASCHERI, 2006; FERREIRA et al., 2012; SILVA, 2012).

O sorvete é uma sobremesa muito consumida no Brasil e, por este motivo, é um ótimo veículo de incorporação de ingredientes funcionais. O objetivo da incorporação é fazer desta sobremesa gelada um 
produto enriquecido nutricionalmente, pois o consumidor moderno deseja alimentos que supram suas exigências de forma saudável e que apresentem alto padrão sensorial (CRUZ et al., 2009).

Uma alternativa que vem crescendo nos últimos anos consiste no aproveitamento de resíduos (principalmente cascas) de certos frutos como matéria prima para a produção de alimentos, perfeitamente passíveis de serem incluídos na alimentação humana. Trata-se de uma proposta plausível, concreta, visto que esses resíduos representam extraordinária fonte de materiais considerados estratégicos para algumas indústrias brasileiras (OLIVEIRA et al., 2002; FERREIRA, et al. 2012).

O presente estudo teve como objetivo realizar a caracterização físico-química da farinha da casca de jabuticaba, bem como desenvolver três formulações de sorvetes (enriquecidos com 0,5 e $10 \%$ desta farinha) e avaliar as características físico-químicas e sensoriais dos mesmos.

\section{MATERIAL E MÉTODOS}

\section{Obtenção das Amostras}

Os frutos de jabuticaba foram coletados na zona rural da fazenda Valinhos, situada no município de Medeiros-MG. Logo após a colheita, os frutos foram selecionados, lavados em água corrente, sanitizados com solução de hipoclorito de sódio (200 mg/kg) e armazenados sobre refrigeração para posterior utilização.

\section{Extração da polpa e obtenção da farinha da casca da jabuticaba (FCJ)}

As jabuticabas foram despolpadas manualmente e, em seguida, as cascas foram secas em estufa de circulação de ar forçado sob uma temperatura de $40{ }^{\circ} \mathrm{C}$ por 72 horas. Em seguida, as cascas foram trituradas em moinho de facas e armazenadas em embalagens laminadas com ausência de luz e oxigênio. Já a polpa foi peneirada para que houvesse a separação da semente (caroço) e então foi concentrada em tacho de camisa dupla até $65^{\circ}$ Brix e armazenada em vidros esterilizados.

\section{Análises físico-químicas da casca da jabuticaba}

As análises da composição centesimal como umidade, cinzas, $\mathrm{pH}$, sólidos solúveis totais (SST), fibra bruta e acidez total titulável (ATT) foram realizadas em triplicata. O teor de umidade foi estimado por meio de aquecimento direto em estufa com circulação forçada de ar a $105^{\circ} \mathrm{C}$, até obtenção de peso constante (IAL, 1985). A fração de cinzas foi obtida gravimetricamente, avaliando-se a perda de peso do material submetido ao aquecimento à $550{ }^{\circ} \mathrm{C}$ em mufla (AOAC, 1997). A determinação do $\mathrm{pH}$ foi feita mediante o método eletrométrico, utilizando-se um pHmetro digital (IAL, 2008). Os teores de SST foram obtidos por leitura direta em refratômetro (marca Atago n.1, 0 32 ${ }^{\circ}$ Brix) e os valores expressos em ${ }^{\circ}$ Brix (PRADO, 2009). A fibra bruta foi determinada pelo método de AOAC (1997) que se baseou na dissolução da amostra, sucessivamente em solução ácida, básica e com acetona. O resíduo não dissolvido constituiu a fibra. A ATT foi determinada de acordo com a metodologia descrita por Pregnolato; Pregnolato (1985).

\section{Formulações e ingredientes utilizados para o processamento dos sorvetes}

Foram produzidas três formulações de sorvetes com adição de diferentes concentrações de FCJ que foram denominadas como $0 \%$ (controle), $5 \%$ e $10 \%$ (correspondendo ao teor de FCJ), com quatro repetições.

Para a elaboração dos sorvetes foram utilizadas as seguintes matérias-primas (Tabela 1): leite integral, creme de leite e leite em pó 
(Molico ${ }^{\circledR}-$ Nestlé, Araçatuba, Brasil); polpa e farinha da casca de jabuticaba (Fazenda Valinhos); açúcar (União, São Paulo, Brasil ${ }^{\circledR}$ ); emulsificante e liga neutra (Duas Rodas ${ }^{\circledR}$, Jaraguá do Sul, Brasil).

Tabela 1 - Formulações dos sorvetes enriquecidos com a farinha da casca da jabuticaba

\begin{tabular}{lccc}
\hline & \multicolumn{3}{c}{ Formulações (\%) } \\
\hline Ingredientes & $0 \%$ & $5 \%$ & $10 \%$ \\
Leite Integral & 40 & 40 & 40 \\
Polpa de Jabuticaba & 18 & 18 & 18 \\
Açúcar & 18 & 18 & 18 \\
Creme de Leite & 12 & 12 & 12 \\
Leite em pó & 10 & 10 & 10 \\
FCJ & 0 & 5 & 10 \\
Liga neutra & 1 & 1 & 1 \\
Emulsificante & 1 & 1 & 1 \\
\hline
\end{tabular}

\section{Processamento dos sorvetes}

Para a fabricação dos sorvetes, foi adicionado aos ingredientes em pó (açúcar, leite em pó, emulsificante e liga neutra) o leite, dando origem à calda. Em seguida foi adicionada a polpa e a FCJ à calda e esta mistura foi homogeneizada por 5 minutos em liquidificador industrial para distribuição uniforme dos ingredientes. Posteriormente, esta mistura foi pasteurizada a $72{ }^{\circ} \mathrm{C}$, por 15 minutos e depois resfriada a $10{ }^{\circ} \mathrm{C}$. Em seguida, foi maturada em geladeira, por $12 \mathrm{~h}$ a $8{ }^{\circ} \mathrm{C}$ para que houvesse a incorporação dos ingredientes. Depois de maturada, a calda foi submetida ao processo de batimento e, com agitação constante da máquina de sorvete, o ar foi incorporado à mistura que, em seguida, foi congelada, dando origem aos sorvetes. $\mathrm{O}$ endurecimento foi realizado em freezer convencional com temperatura entre $-18{ }^{\circ} \mathrm{C}$ e $-20^{\circ} \mathrm{C}$. Uma vez endurecido, o produto foi armazenado em potes previamente esterilizados e identificados.

\section{Análises físico-químicas dos sorvetes enriquecidos com a farinha da casca da jabuticaba}

Depois de fabricados, os diferentes sorvetes foram submetidos às análises físico-químicas de $\mathrm{pH}, \mathrm{SST}$, ATT, umidade e cinzas. A determinação do $\mathrm{pH}$ foi realizada mediante o método eletrométrico, utilizando-se um pHmetro digital (IAL, 2008). O teor de SST foi obtido por leitura direta em refratômetro (marca Atago n.1 $0 \sim 32{ }^{\circ} \mathrm{Brix}$ ) e os valores expressos em ${ }^{\circ}$ Brix (PRADO, 2009). A ATT foi determinada de acordo com a metodologia descrita por Pregnolato; Pregnolato (1985). O teor de umidade foi estimado por meio de aquecimento direto em estufa com circulação forçada de ar a $105^{\circ} \mathrm{C}$, até obtenção de peso constante (IAL, 1985). A fração de cinzas foi obtida, gravimetricamente, avaliando-se a perda de peso do material submetido ao aquecimento a $550^{\circ} \mathrm{C}$ em mufla (AOAC, 1997).

\section{Análise de Overrun}

O overrun foi determinado de acordo com o método descrito por Whelan et al. (2008). Volumes iguais $(50 \mathrm{~mL})$ de sorvete foram pesados e o overrun foi calculado conforme a Equação 1.

Overrun $(\%)=\frac{\text { peso da mistura base peso do sorvete } \times 100}{\text { Peso do sorvete }}$

\section{Análise sensorial dos sorvetes}

Para a avaliação sensorial dos sorvetes, foram utilizados 50 provadores não treinados e o teste foi realizado em cabines individuais, durante o período matutino (09:00 às 11:00). Foi aplicado o teste de aceitabilidade, utilizando-se escala hedônica estruturada de nove pontos (ABNT, 1998), variando de "1" (desgostei extremamente) a "9" (gostei extremamente). Os atributos avaliados foram: aparência, sabor, textura e aspecto global. 
Os provadores também foram questionados quanto à intenção de compra do produto e utilizou-se escala hedônica de 5 pontos, variando de 5 "certamente compraria" e 1 "certamente não compraria”.

\section{Análise estatística}

Os dados obtidos foram analisados estatisticamente por análise de variância (ANOVA) pelo programa Sisvar e por teste de médias de Tukey. As diferenças foram consideradas significativas quando $\mathrm{p}<0,05$ (FERREIRA, 2011).

\section{RESULTADOS E DISCUSSÃO}

\section{Análise físico-química da farinha da casca da jabuticaba}

$\mathrm{O}$ valor de $\mathrm{pH}$ da farinha da casca de jabuticaba (Tabela 2) foi semelhante ao $\mathrm{pH}$ encontrado por Lima et al. (2009) para a casca de jabuticaba das variedades Sabará ( $\mathrm{pH} \mathrm{3,39)} \mathrm{e} \mathrm{Paulista} \mathrm{(} \mathrm{pH} \mathrm{3,47).} \mathrm{Arsego} \mathrm{et} \mathrm{al.}$ (2003) mostraram que o $\mathrm{pH}$ da fruta in natura é importante na retenção de antocianinas, uma vez que em $\mathrm{pH}<3,0$ esses componentes são mais estáveis frente a fatores que aceleram a decomposição.

O valor de SST foi de $4{ }^{\circ}$ Brix, entretanto, de acordo com Redies et al. (2006), é de conhecimento geral em processamento de frutas e hortaliças, que o teor de SST na fruta está diretamente relacionado com a lucratividade. Frutas com maior teor de sólidos solúveis reduzem, proporcionalmente, a quantidade de açúcar a ser adicionado no produto, para atingir a concentração de sólidos estabelecida para o produto final.
Por outro lado, é cada vez maior o número de consumidores que apresentam restrição quanto ao consumo de açúcar, favorecendo assim a ingestão deste produto.

A acidez total titulável encontrada foi de 9,4 g/100g e caracteriza a farinha como um produto ácido. Este valor pode indicar a presença de componentes antioxidantes, indicando que esta fruta pode reduzir a ação dos radicais livres no organismo, entretanto são necessárias mais pesquisas. Segundo os autores Chitarra; Chitarra (2005), a acidez de um fruto é dada pela presença dos ácidos orgânicos que servem de substratos para a respiração. Assim, a variação da acidez pode ser um indicativo do estágio de maturação do fruto, já que a acidez decresce em função do avanço da maturação.

O teor de umidade foi de $16,13 \mathrm{~g} / 100 \mathrm{~g}$ e o valor expressa semelhança com o trabalho realizado por Vieites et al. (2011), que encontrou $14,45 \mathrm{~g} / 100 \mathrm{~g}$ para a casca de jabuticaba. Já o resultado de cinzas, se destacou por apresentar o valor de 4,23 g/100g o que poderá suprir parte da IDR (Ingestão Diária Recomendada) de minerais. Conforme a Legislação (ANVISA, 2005), esse resultado comprova que a FCJ pode ser considerada um alimento enriquecido com minerais contribuindo dessa maneira para a manutenção saudável do organismo. O resultado obtido vem de encontro à pesquisa realizada por Vieites et al. (2011), que detectou a presença de 4,26 g/100g de cinzas na FCJ. Os minerais são necessários para o desempenho das funções normais celulares, uma vez que, regulam a ativação de diversas enzimas, o equilíbrio ácido-base, a pressão osmótica, a atividade muscular e nervosa. Além disso, facilitam a

Tabela 2 - Composição físico-química da farinha da casca da jabuticaba (média \pm desvio padrão)

\begin{tabular}{cccccc}
\hline $\mathrm{pH}$ & $\begin{array}{c}\mathrm{SST} \\
\left({ }^{\circ} \text { Brix }\right)\end{array}$ & $\begin{array}{c}\text { Acidez total titulável } \\
(\mathrm{g} \text { ácido cítrico/100g) }\end{array}$ & $\begin{array}{c}\text { Umidade } \\
(\mathrm{g} / 100 \mathrm{~g})\end{array}$ & $\begin{array}{c}\text { Cinzas } \\
(\mathrm{g} / 100 \mathrm{~g})\end{array}$ & $\begin{array}{c}\text { Fibra Bruta } \\
(\mathrm{g} / 100 \mathrm{~g})\end{array}$ \\
\hline $3,27 \pm 0,45$ & $4,00 \pm 0,42$ & $9,4 \pm 0,13$ & $16,13 \pm 0,33$ & $4,23 \pm 0,54$ & $5,60 \pm 0,22$ \\
\hline
\end{tabular}


transferência de compostos essenciais através das membranas, auxiliam a formação dos ossos, composição da hemoglobina, expressão gênica, metabolismo de carboidratos e, em alguns casos, fazem parte dos elementos constituintes dos tecidos do organismo (VIEITES et al., 2011).

As fibras são importantes agentes que influenciam a microbiota do trato gastrointestinal de humanos. O teor de fibra bruta encontrado na FCJ foi de 5,60 g/100g e para um alimento ser considerado como fonte de fibras é necessário que o mesmo contenha, no mínimo, $3 \mathrm{~g}$ de fibras por porção de $100 \mathrm{~g}$ e, desta forma, a FCJ se enquadra neste atributo. Estudos relacionam as fibras à prevenção de doenças como diverticulite, câncer de cólon, obesidade, problemas cardiovasculares, diabetes e redução dos níveis séricos de lipídeos (SALGADO et al., 2008; FERREIRA et al., 2012).

Vieites et al. (2011) detectou que as cascas de jabuticabas analisadas continham $15,26 \mathrm{~g} / 100 \mathrm{~g}$ de fibra bruta e em trabalho realizado por Ferreira et al. (2012), que desenvolveram cookies com casca de jabuticaba, foram encontrados valores de 15,25 g/100g. Ambos os trabalhos caracterizam a casca de jabuticaba como alimento fortificado com fibras.

De modo geral, os resultados obtidos quando comparados com os encontrados por outros autores, em geral, demonstram que pequenas variações nutricionais podem ser verificadas e são atribuídas às diferenças entre as amostras quanto às linhagens e condições de cultivo, como temperatura, luz, tipo de solo e condições de nutrição, as quais exercem demasiada influência sobre a qualidade nutricional (AYERZA, 2009).

\section{Análises físico-químicas dos sorvetes}

$\mathrm{O} \mathrm{pH}$ dos sorvetes analisados variaram de 4,2 à 6,0 e apresentaram diferenças em todos os tratamentos $(\mathrm{p}<0,05)$ (Tabela 3$)$. A amostra com 10\% apresentou menor $\mathrm{pH}$ e foi a mais ácida. Essa diminuição pode ser resultante da maior concentração de FCJ adicionada. Em comparação com outras pesquisas (PEREIRA et al., 2011; FERRAZ et al., 2012), o valor de $\mathrm{pH}$ para este sorvete pode ser considerado relativamente baixo. Entretanto, os sorvetes com $0 \%$ e $5 \%$ de FCJ encontram-se próximo à neutralidade e se assemelham aos resultados verificados por Santana et al. (2003) que foram de 5,53 à 5,87 para sorvetes elaborados com diferentes genótipos de mamões. Em geral, todos os sorvetes apresentaram $\mathrm{pH}$ mais elevado que a FCJ, fato justificado devido a incorporação de ingredientes com menor acidez como é o caso do leite (ingrediente majoritário na formulação dos sorvetes).

Tabela 3 - Composição físico-química dos sorvetes enriquecidos com farinha da casca da jabuticaba (média \pm desvio padrão)

\begin{tabular}{cccccc}
\hline Tratamentos ${ }^{(1)}$ & $\mathrm{pH}$ & $\begin{array}{c}\text { Sólidos solúveis } \\
\text { totais } \\
\left({ }^{\mathrm{o}} \mathrm{Brix}\right)\end{array}$ & $\begin{array}{c}\text { Acidez total } \\
\text { titulável }(\mathrm{g} \text { ácido } \\
\text { cítrico/100g) }\end{array}$ & $\begin{array}{c}\text { Umidade } \\
(\mathrm{g} / 100 \mathrm{~g})\end{array}$ & $\begin{array}{c}\text { Cinzas } \\
(\mathrm{g} / 100 \mathrm{~g})\end{array}$ \\
\hline $0 \% \mathrm{FCJ}^{*}$ & $6,00 \pm 0,04^{\mathrm{a}}$ & $34,00 \pm 0,09^{\mathrm{a}}$ & $1,05 \pm 0,11^{\mathrm{a}}$ & $11,10 \pm 0,04^{\mathrm{a}}$ & $0,90 \pm 0,12^{\mathrm{a}}$ \\
$5 \% \mathrm{FCJ}$ & $5,30 \pm 0,05^{\mathrm{b}}$ & $34,00 \pm 0,33^{\mathrm{a}}$ & $1,08 \pm 0,09^{\mathrm{b}}$ & $6,20 \pm 0,04^{\mathrm{b}}$ & $1,01 \pm 0,22^{\mathrm{b}}$ \\
$10 \% \mathrm{FCJ}$ & $4,20 \pm 0,18^{\mathrm{c}}$ & $36,00 \pm 0,22^{\mathrm{a}}$ & $1,12 \pm 0,03^{\mathrm{c}}$ & $3,30 \pm 0,04^{\mathrm{c}}$ & $1,07 \pm 0,08^{\mathrm{b}}$ \\
\hline
\end{tabular}

a Médias na mesma coluna acompanhadas com letras iguais não diferem entre si pelo teste de Tuckey $(\mathrm{p}<0,05)$.

* FCJ: farinha de casca de jabuticaba 
Em relação à análise de sólidos solúveis totais os valores encontrados representam os compostos que são solúveis em água e os resultados obtidos foram de 34 a $36^{\circ}$ Brix, não apresentando diferença significativa $(\mathrm{p}<0,05)$ para as diferentes formulações. Esses valores mais elevados são devido às várias fontes de açúcar adicionadas, como a sacarose, e também devido ao leite. Conforme Perrone et al. (2011), um elevado teor de Brix pode influenciar na aceitação do produto, pois está diretamente relacionado com o sabor.

A acidez total titulável dos sorvetes é um parâmetro influenciado pela fruta utilizada e tendo em vista que a casca de jabuticaba possui 9,4 g de ácido cítrico em $100 \mathrm{~g}$, os sorvetes não expressaram coerência com este dado, pois apresentaram baixa acidez. Este fato pode ser explicado pelas diversas fontes de açúcares e leite adicionados o que de certa forma, podem influenciar na redução do ácido. As amostras apresentaram diferença significativa $(\mathrm{p}<0,05)$, o sorvete com $10 \%$ apresentou maior acidez provavelmente devido a maior porcentagem de casca adicionada nesta formulação. Do ponto de vista industrial, os elevados teores de ácido presentes nos produtos lácteos diminuem a necessidade de adição de acidificantes e propicia melhoria nutricional, segurança alimentar e qualidade sensorial (ROCHA et al., 2001).

Os valores encontrados para umidade apresentaram também diferença estatística entre todas as amostras $(p<0,05)$ e conclui-se que a adição de FCJ reduziu a umidade dos sorvetes. Isso porque segundo Soler; Veiga (2001), quanto maior a umidade, menor a concentração de sólidos. Os sólidos são desejados, pois atuam melhorando a textura e a cremosidade do produto elaborado.

As formulações com 5\% e 10\% FCJ não diferiram estatisticamente $(\mathrm{p}<0,05)$ para os teores de cinzas. Esses valores são justificados, pois segundo Sousa et al. (2010), os sorvetes de frutas são ricos em diversos sais minerais (cálcio, sódio, potássio, magnésio, etc.) devido a presença do leite e dos minerais na própria polpa. Foi detectado que a FCJ apresentou elevados teores deste nutriente, entretanto, quando comparado com os resultados dos sorvetes, observa-se um decréscimo de cinzas. Provavelmente ocorreu alguma perda durante a realização da análise, pois, sabe-se que algumas substâncias inorgânicas podem sofrer volatilização durante a secagem ou podem sofrer interação com algum componente da amostra reduzindo os seus teores. Santana et al. (2003) ao analisarem sorvetes encontraram valores na faixa de $0,50 \%$ e $0,33 \%$ de cinzas, resultados inferiores aos encontrados neste estudo.

\section{Overrun}

$\mathrm{O}$ ar presente no sorvete fornece uma textura mais suave e influencia as propriedades físicas de derretimento e textura. Todavia, não é apenas a quantidade de ar incorporado (overrun), mas também a distribuição e o tamanho das células de ar que influenciam essas propriedades. Diversos fatores são determinantes para o desenvolvimento da incorporação de ar em sorvetes, tais como: conteúdo de sólidos totais (quanto maior o conteúdo de sólidos totais, maior será a incorporação de ar ao sorvete); da quantidade de gordura (quanto maior o teor de gordura, menor será o ar incorporado); do tipo e quantidade de emulsificantes e estabilizantes; e do tipo do equipamento de congelamento (as produtoras horizontais (contínuas) incorporam maiores quantidades de ar que as produtoras verticais (batelada)) (CHANG; HARTEL, 2002a; CHANG; HARTEL, 2002b; SOFJAN; HARTEL, 2004; PEREIRA et al., 2011).

Os resultados da análise de overrun que foram de $88 \%, 82 \%$ e $77 \%$ respectivamente para os sorvetes com $0 \%, 5 \%$ e $10 \%$ FCJ, com diferença significativa $(\mathrm{p}<0,05)$ entre elas. A formulação com $0 \%$ foi a que obteve 
melhor resultado, pois apresentou a maior incorporação de ar dentre os sorvetes analisados. O overrun diminuiu conforme o aumento da adição da FCJ e isso pode ter ocasionado a diminuição da água livre disponível nos sorvetes. Desta forma, o sorvete com $10 \%$, por ser a amostra com maior quantidade de FCJ, apresentou o overrun mais baixo por ser a formulação mais complexa do ponto de vista estrutural (PEREIRA et al., 2011).

Pereira et al. (2011) ao estudarem a incorporação de ar em sorvetes que tiveram o leite em pó substituído por extrato hidrossolúvel de soja (EHS), obtiveram os resultados de $77,28 \%, 89,06 \%, 77,43 \%$, e $64,60 \%$ de overrun para as formulações adicionados de $0 \%, 10 \%, 20 \%$, e $30 \%$ de EHS. Os autores concluíram que a incorporação de ar foi influenciada pelo nível de substituição, porém, de forma não uniforme. O maior overrun foi obtido para amostra com $10 \%$ EHS e o menor para a amostra com $30 \%$ EHS.

\section{Avaliação sensorial dos sorvetes}

Os quatro atributos avaliados sensorialmente (Tabela 4) receberam notas acima de 7 , demonstrando que os provadores gostaram e aprovaram os sorvetes desenvolvidos.

Em relação à aparência, os sorvetes alcançaram médias correspondentes aos termos da escala hedônica "gostei moderadamente", mostrando uma elevada aceitação dos produtos. Para os provadores não houve prevalência entre os produtos quanto à aparência, pois não apresentaram diferença significativa $(\mathrm{p}<0,05)$. Vale destacar que a primeira impressão que se tem de um alimento é geralmente visual, sendo que este atributo é um dos aspectos considerados fundamentais na qualidade e aceitação dos alimentos.

De acordo com Teixeira et al. (1987), para que um produto seja considerado como aceito, em termos de suas propriedades sensoriais, é necessário que obtenha um índice de aceitabilidade de, no mínimo, 70\%, porcentagem compatível as notas atribuídas aos sorvetes.

Os sorvetes processados com $0 \%$ e $5 \%$ de FCJ se destacaram quanto aos seus sabores, alcançaram média correspondente a "gostei muito" e diferiram significativamente $(\mathrm{p}<0,05)$ do sorvete preparado com $10 \%$ FCJ. Entretanto, observa-se que todos os sorvetes elaborados apresentaram adequada aceitação sensorial com relação ao sabor, pois obtiveram médias superiores a 7 .

Quanto à textura, os sorvetes alcançaram médias correspondentes a "gostei moderadamente" e a única formulação que apresentou diferença significativa $(\mathrm{p}<0,05)$ foi a amostra com $10 \%$ FCJ. Esse resultado se deve provavelmente pela maior quantidade de FCJ adicionada e consequentemente maior teor de fibra presente neste sorvete. Mesmo com esta variação, estes valores mostram uma elevada aceitação dos produtos quanto a este atributo. Em resumo, os únicos atributos que se diferenciaram estatisticamente $(\mathrm{p}<0,05)$ foram sabor, textura e aspecto

Tabela 4 - Aceitabilidade dos sorvetes enriquecidos com farinha da casca da jabuticaba

\begin{tabular}{ccccc}
\hline Tratamentos & Aparência & Sabor & Textura & Aspecto Global \\
\hline $0 \%$ FCJ $^{*}$ & $7,89^{\mathrm{a}}$ & $8,26^{\mathrm{a}}$ & $7,89^{\mathrm{a}}$ & $8,18^{\mathrm{a}}$ \\
$5 \% \mathrm{FCJ}$ & $7,80^{\mathrm{a}}$ & $8,10^{\mathrm{a}}$ & $7,86^{\mathrm{a}}$ & $7,98^{\mathrm{a}}$ \\
$10 \% \mathrm{FCJ}$ & $7,80^{\mathrm{a}}$ & $7,17^{\mathrm{b}}$ & $7,45^{\mathrm{b}}$ & $7,39^{\mathrm{b}}$ \\
\hline
\end{tabular}

a Médias na mesma coluna acompanhadas com letras iguais não diferem entre si pelo teste de Tuckey $(\mathrm{p}<0,05)$. FCJ: farinha de casca de jabuticaba 
global da formulação com $10 \%$ de FCJ. Esses resultados mostram que os consumidores não detectaram diferença estatística $(\mathrm{p}<0,05)$ nas amostras com $0 \%$ e $5 \%$ de FCJ e este fato impulsiona o uso desta farinha principalmente por ser uma fonte expressiva de fibras.

Os provadores não relataram na ficha de avaliação nenhuma observação quanto à percepção da presença de casca de jabuticaba e essa não foi considerada um interferente negativo nas formulações dos sorvetes o que pode impulsionar o uso deste ingrediente.

Em trabalho realizado por Alves (2011), foi adicionada casca de jabuticaba em iogurte e de acordo com a análise sensorial realizada, o mesmo recebeu notas que se situaram entre 6 (gostei ligeiramente) e 7 (gostei moderadamente). Em exceção, incluíram-se os atributos cor e aparência que receberam notas mais baixas. Gonsalves et al (2015), desenvolveram um iogurte funcional adicionado de geleia e fibra da casca da jabuticaba e como resultado foi verificado que a adição desses ingredientes não influenciou na avaliação sensorial das amostras e os produtos foram considerados comercialmente aceitos pelos julgadores.

Santos et al. (2015) elaboraram duas formulações de geleias de jabuticaba que foram denominada GC (adicionada de $25 \%$ de cascas da jabuticaba) e GE (elaborada a partir do extrato do fruto). Como resultado sensorial, os autores verificaram que as geleias diferiram entre si. Para as formulações GC e GE foram encontradas médias de 7,4 e 8,3 para o atributo sabor e 6,9 e 8,3 para textura respectivamente. Os autores concluíram que a geleia fabricada com o extrato da jabuticaba foi mais bem aceita para os atributos avaliados.

Ferreira et al. (2012), ao verificarem os atributos sensoriais dos cookies fabricados com farinha da casca da jabuticaba, concluíram que a utilização desta farinha influenciou positivamente a textura/maciez dos biscoitos e sugeriram o uso de até 5\% a fim de não haver influências negativas quanto à aceitação.
Finalmente, quando questionados sobre a intenção de compra dos sorvetes, os mesmos apresentaram notas de 4,5; 4,5 e 4,0 para as formulações $0 \%, 5 \%$ e $10 \%$ respectivamente. Esses resultados representam que os consumidores aceitaram os produtos e estão seguros quanto à compra dos mesmos. Mesmo estes sorvetes sendo elaborado com ingredientes que os consumidores não estão acostumados a consumir, como é o caso da FCJ, este fato não causou dúvida na hora dos consumidores avaliarem se comprariam ou não os sorvetes. Um fato que pode fortalecer a decisão na hora da compra, é a conscientização da qualidade nutricional que os mesmos podem oferecer. Entretanto, é necessário um maior investimento em campanhas governamentais, uma vez que a casca de jabuticaba é rica em nutrientes e podem prevenir o surgimento de doenças, segundo pesquisas científicas (LIMA et al., 2008; REYNERTSON et al., 2008; SANTOS; MEIRELES, 2009; SANTOS et al., 2010; CAVALCANTI et al., 2011; SILVA, 2012;).

\section{CONCLUSÕES}

A farinha da casca da jabuticaba apresenta elevados níveis de cinzas e fibras, podendo ser considerada uma importante fonte nutricional além de receber alegação de funcional como produto com alto teor de fibra. $\mathrm{O}$ enriquecimento de sorvetes ao nível de $5 \%$ com farinha da casca de jabuticaba apresenta forte potencial à comercialização, já que proporciona aos produtos elevação no valor nutricional sem afetar as características sensoriais e contemplam a demanda dos consumidores por produtos simultaneamente atrativos e saudáveis.

\section{REFERÊNCIAS}

AGÊNCIA NACIONAL DE VIGILÂNCIA SANITÁRIA (ANVISA). Resolução RDC 
$\mathrm{n}^{\mathrm{o}} 269$, de 22 de setembro de 2005. Regugulamento técnico sobre a ingestão diária recomendada (IDR) de proteína, vitaminas e minerais. Diário Oficial da República Federativa do Brasil, Brasília, 23 set. 2005.

ALISSA, E. M.; FERNS, G. A. Functional foods and nutraceuticals in the primary prevention of cardiovascular diseases. Journal of Nutrition and Metabolism, v. 2012, ID 569486, 2012.

\section{ALVES, A. P. C. Casca de jabuticaba (Plinia} jaboticaba (Vell.) Berg): processo de secagem e uso como aditivo em iogurte. Lavras: UFLA, 2011. 90 p.

ARSEGO, J. L. et al. Cinética da extração de antocianinas em frutos de framboesa (Rubus idaeus) e amora preta (Rubus fructicosus). In: Congresso Brasileiro de Fruticultura, 16., 2002, Belém. Anais... Belém: Sociedade Brasileira de Fruticultura, 2002. 1 CD-ROM.

ASCHERI, D. P. R., ASCHERI, J. L. R., CARVAlHO, C. W. P. de. Caracterização da farinha de bagaço de jabuticaba e propriedades funcionais dos extrusados. Ciência e Tecnologia de Alimentos, v. 26, n. 4, p. 897-905, 2006.

\section{ASSOCIAÇÃO BRASILEIRA DE NORMAS} TÉCNICAS (ABNT). NBR 14141: escalas utilizadas em análise sensorial de alimentos e bebidas. Rio de Janeiro, 1998. 3 p.

ASSOCIATION OF OFFICIAL ANALYTICAL CHEMISTS (AOAC). Official methods of analysis of the AOAC International. 16th ed. Gaitherburg: AOAC, 1997.

AYERZA, R. The seed's protein and oil content, fatty acid composition and growing cycle length of a single genotype of Chia (Salvia hispanica L.) as affected by environmental factors. Journal of Oleo Science, v. 58, n. 7, p. 347-354, 2009.

CAVAlCANTI, R. N.; VEGGI, P. C.; MEIRELES, M. A. A. Supercritical fluid extraction with a modifier of antioxidant compounds from jabuticaba (Myrciaria cauliflora) byproducts: economic viability. Procedia Food Science, v. 1, p. 1672- 1678, 2011.

CHANG, Y.; HARTEL, R. W. Stability of air cells in ice cream during hardening and storage. Journal of Food Engineering, v. 55, n. 1, p. 59-70, 2002a.

CHANG, Y.; HARTEL, R. W. Development of air cells in a batch ice cream freezer. Journal of Food Engineering, v. 55, n. 1, p. 71-78, 2002b.

CHITARRA, M. I. F.; CHITARRA, A. B. Póscolheita de frutos e hortaliças: fisiologia e manuseio. $2^{\mathrm{a}}$ ed. Lavras: UFLA, 2005. 785 p.

CRUZ, A. G. et al. Ice-cream as a probiotic food carrier. Food Research International, v. 42, n. 9, p. 1233-1239, 2009.

FERRAZ, J. L. et al. Sensory acceptance and survival of probiotic bacteria in ice cream produced with different overrun levels. Journal of Food Science, v. 77, n. 1, p. 2428, 2012.

FERREIRA, A. E. et al. produção, caracterização e utilização da farinha de casca de jabuticaba em biscoitos tipo cookie. Alimentos e Nutrição, v. 23, n. 4, p. 603-607, 2012.

FERREIRA, D. F. Sisvar: A computer statistical analysis system. Ciência e Agrotecnologia, v. 35, n. 6, p. 1039-1042, 2011.

GONSALVES, R. T. et al. Características físicas e químicas do iogurte funcional 
enriquecido com geleia e fibra de casca de jabuticaba (Myrciaria jaboticaba (vell) berg). In: CONGRESSO INTERNACIONAL DO LEITE, 12., 2013, Porto Velho. Anais eletrônicos... Porto Velho: Embrapa, 2013. Disponível em: <http://www.cnpgl. embrapa.br/congresso2013/anais/artigos/ qualidade/642.pdf>. Acesso em: 13 fev. 2015.

INSTITUTO ADOLF LUTZ. Métodos químicos e físicos para análise de alimentos. $3^{\mathrm{a}}$ ed. São Paulo, 1985. 78 p.

INSTITUTO ADOLFO LUTZ. Métodos físico-químicos para análise de alimentos. $4^{\mathrm{a}}$ ed., 1 ed. digital. São Paulo: Instituto Adolfo Lutz, 2008. 1020 p.

INSTITUTO BRASILEIRO DE GEOGRAFIA E ESTATÍSTICA (IBGE). POF 20082009 Antropometria e estado nutricional 398 de crianças, adolescentes e adultos no Brasil. Rio de janeiro: IBGE, 2010. 130 p.

LIMA, A. J. B. Caracterização e atividade antioxidante da jabuticaba [Myrciaria cauliflora (Mart.) O. Berg]. 2009. 159 p. Tese (Doutorado em Agroquímica) - Universidade Federal de Lavras, Lavras, 2009.

LIMA, A. J. B. et al. Caracterização química do fruto jabuticaba (Myrciaria cauliflora Berg) e de suas frações. Archivos Latinoamericanos de Nutricion, v. 58, n. 4, p. 416-421, 2008.

OLIVEIRA, L. F. et al. Aproveitamento alternativo da casca do maracujá-amarelo (Passiflora edulis F. FLAVICARPA) para produção de doce em calda. Ciência e Tecnologia de Alimentos, v. 22, n. 3, p. 259-262, 2002.

PEREIRA, G. G. et al. Influence of the partial substitution of skim milk powder for soy extract on ice cream structure and quality. European Food Research and Technology, v. 232, n. 6, p. 1093-1102, 2011.

PERRONE, I. T. et al. Influência de diferentes espessantes nas características sensoriais do doce de leite para confeitaria. Revista do Instituto de Laticínios Cândido Tostes, v. 66, n. 379 , p. 45-50, 2011.

PRADO, A. Composição fenólica e atividade antioxidante de frutas tropicais. 2009. 107 p. Dissertação (Mestrado em Ciências de Alimentos) - Escola Superior de Agricultura "Luiz de Queiroz", Universidade de São Paulo, Piracicaba, 2009.

PREGNOLATTO, W.; PREGNOLATTO, N. P. Normas Analíticas do Instituto Adolfo Lutz: métodos químicos e físicos para análise de alimentos. São Paulo: Instituto Adolfo Lutz, 1985. v. 1, 533 p.

REDIES, C. R. et al. Caracterização físicoquímica de mirtilo (vacinium aschei reade) para aplicação na elaboração de toppings. In: CONGRESSO DE INICIAÇÃO CIENTIFICA, 15., 2006, Pelotas. Anais eletrônicos... Pelotas: UFPEL, 2006. Disponível em: <http://www2. ufpel.edu.br/cic/2006/resumo_expandido/CA/ CA_01214.pdf $>$. Acesso em: 13 fev. 2015.

REYNERTSON, K. A. et al. Quantitative analysis of antiradical phenolic constituents from fourteen edible Myrtaceae fruits. Food Chemistry, v. 109, n. 4, p. 883-890, 2008.

ROCHA, M. C. et al. Efeito do uso de biofertilizante agrobio sobre as características físico-químicas na pós-colheita do maracujáamarelo (Passiflora edulis f. flavicarpa Deg.) no município de Taubaté. Revista Biociências, v. 7, n. 2, p. 7-13, 2001.

SALGADO, J. M. et al. Efeito do abacate 
(Persea americana Mill) variedade hass na lipidemia de ratos hipercolesterolêmicos. Ciência e Tecnologia de Alimentos, v. 28, n. 4, p. 922-928, 2008.

SANTANA, L. R. R.; MATSUURA, F. C. A. U.; CARDOSO, R. L. Genótipos melhorados de mamão (carica papaya l.): avaliação tecnológica dos frutos na forma de sorvete. Ciência e Tecnologia de Alimentos, v. 23, supl., p. 151-155, 2003.

SANTOS, D. T.; MEIRELES, M. A. A. Jabuticaba as a source of functional pigments. Pharmacognosy Reviews, v. 3, n. 5, p. 127132, 2009.

SANTOS, D. T.; VEGGI, P. C.; MEIRELES, M. A. A. Extraction of antioxidant compounds from Jabuticaba (Myrciaria cauliflora). Journal of Food Engineering, v. 101, n. 1, p. 23-31, 2010.

SANTOS, J. M. et al. Elaboração e Avaliação Sensorial de Geléia de Jabuticaba (Myciaria spp.) adicionada de cascas. In: JORNADA CIENTÍFICA DA UEMS, 2., 2015, Naviraí. Anais eletrônicos... Naviraí: UEMS. Disponível em: <http://www.uems.br/navirai/ acad/JCN/2JCN/AR-JMS-2JCN.pdf $>$. Acesso em: 12 fev. 2015.

SILVA, Mariana Casagrande. Aproveitamento do resíduo de jabuticaba (Myrciaria cauliflora) para obtenção de pigmento com propriedades funcionais. 2012. 122f.
Dissertação (Mestrado em Engenharia de Alimentos) - Universidade de São Paulo, Pirassununga, 2012.

SOFJAN, R. P.; HARTEL, R. W. Effects of overrun on structural and physical characteristics of ice cream. International Dairy Journal, v. 14, n. 3, p. 255-262, 2004.

SOLER, M. P.; VEIGA, P. G. Sorvetes. Campinas: ITAL; CIAL, 2001. 68 p. (Especial, 1).

SOUZA, J. C. B. et al. Sorvete: composição, processamento e viabilidade da adição de probiótico. Alimentos e Nutrição, v. 21, n. 1, p. 153-163, 2010.

TEIXEIRA, E., MEINERT, E., BARBETTA, P.A. Análise sensorial dos Alimentos, Florianópolis: UFSC, 1987. 182p.

VIEITES, R. L. et al. Caracterização físicoquímica, bioquímica e funcional da jabuticaba armazenada sob diferentes temperaturas. Revista Brasileira de Fruticultura, v. 33, n. 2, p. 362-375, 2011.

WHELAN, A. P. et al. Physicochemical and sensory optimisation of a low glycemic index ice cream formulation. International Journal of Food Science and Technology, v. 43, n. 9, p. 1520-1527, 2008.

WORLD HEALTH ORGANIZATION (WHO). Diet, nutrition and the prevention of chronic diseases. Geneva, 2003. 149 p. 